\title{
Power and the teaching of medical ethics
}

\author{
Barbara Nicholas Christchurch School of Medicine, Christchurch, New Zealand
}

\begin{abstract}
This paper argues that ethics education needs to become more reflective about its social and political ethic as it participates in the construction and transmission of medical ethics. It argues for a critical approach to medical ethics and explores the political context in medical schools and some of the peculiar problems in medical ethics education.
\end{abstract}

(Fournal of Medical Ethics 1999;25:507-513)

Keywords: Medical education; ethics

"... our knowing is essentially imaginative, that is, an act of organising social reality around dominant, authoritative images. This means that the assumptions that have long had unexamined privilege among us are now seen to be sturdy, powerful acts of imagination, reinforced, imposed, and legitimated by power."

\section{Introduction}

The teaching of medical ethics is never neutral. In many subtle ways teachers are able to influence students' approaches to their work, emphasising some issues, criticising others, enculturating them into particular approaches. Teachers are constantly choosing what language to use, how to present cases, what is significant information to include in the presentation of a case, how to structure the conversation, and what input to affirm, question or challenge. In all engagements with medical students ethics educators are not only teaching them the professional codes and expectations, the skills of analysis and argument. They are also endeavouring to provide students with the lenses through which they will examine the world and their profession's continuing practice. The choice of lens offered to students is itself a political and ethical act in that different lenses will orientate students towards varying distributions of power and valuing of elationships.

In the New Zealand context, recent medical history has provided a sharp focus for this choice. In 1987 "The unfortunate experiment" (as it came to be called) came to light. This was a study carried out at National Women's Hospital in
Auckland, over more than twenty years, in which women who returned positive cervical smears after initial treatment, were followed up and observed in order to test whether or not carcinoma in situ did lead to cervical cancer. The women were not told they were part of a research programme. Nor did they know that they were being denied normal treatment, or even that what they had was a possible precursor to cervical cancer. Some women died and others required mutilating but avoidable surgery. Despite protests from some medical staff within the hospital the research only came to light and was censured after a journalist and a university lecturer picked up the issue through critical reading of a medical article, and published the story in a popular magazine, Metro. $^{2}$ The subsequent enquiry revealed to the public the attitudes to women and other patients that made such abusive conduct possible, and the difficulties of challenging those in medical power.

Judge Cartwright's report, ${ }^{3}$ which followed the government enquiry, made a number of recommendations, including that Auckland medical students should be taught about this aspect of medical history. (Otago medical school also took up this suggestion.) Introducing medical students to this story, and exploring the issues it raises, emphasises the extent to which teachers of ethics, like all educators, offer particular interpretative lenses. Various interpretations of the Cartwright report are available. In the corridors of medical practice, some have seen it as a feminist, doctor-hating plot, others as an effective revelation of medical abuse and a timely and necessary criticism of medical practice. How should the story be told? To serve what purpose? There is no objective way to tell this story, no value-free place to stand.

Such situations remind those of us who teach, that teaching is a political and ethical activity. We provide students with the skills and frameworks through which they will structure and organise the world. We are active participants in the process through which they decide what is important or unimportant, what questions are interesting, and 
what criteria to use to judge the adequacy of any argument or evidence. Indeed, we (and they) judge their success by their ability to think and "know" as we do, and in so doing we contribute to maintaining or transforming the status quo.

Within a positivist view of knowledge and of education such a position may be defensible. However, the limitations of such a view are now widely recognised. Foucault, ${ }^{4}$ for instance, has uncovered some of the connections between power and knowledge, and feminists have highlighted the extent to which the social and political positioning of the knower affects understandings in disciplines as diverse as science ${ }^{5}$ and theology. ${ }^{67}$

In educational theory, institutions such as schools and universities are now recognised as sites of cultural reproduction, where dominant social relations are taught. There is an extensive literature within critical education (much of it inspired by and extending Paulo Friere's work) that questions curriculum for the social world it seeks to (re)produce; explores education as an emancipatory process or praxis; encourages the teaching and practice of critical reflection; examines the politics of difference as it functions in the classroom, and develops and argues for alternative classroom practices that will bring to voice those whose experiences are silenced within traditional educational institutions. Entwined through all these debates is an orientation to education that it should function to transform social relationships, and should seek to liberate and to heal, at a structural as well as individual level.

\section{Relationships of social power}

One distinctive feature of critical education is that it makes explicit what is frequently implicit, ie the educator is not outside the construction or maintenance of relationships of social power, but an integral part of their reproduction. Thus the educator's position is always challengeable, always open to debate and consideration. Educators are both responsible and accountable for the power they use. In much mainstream education, the agenda of education is frequently assumed, and hence unexamined, but in critical education the agenda is always open to questioning, always a subject of discussion.

Such an approach to education has a great deal to offer medical ethics education as it begins to develop a more critical approach to its own position vis a vis medical discourse. From both a practical and a philosophical direction it is becoming necessary to reflect on the practice of medical ethics education. What or whose construction of knowledge, whose social power, does a particular form of education support? Who is implicitly affirmed by an educational practice Medical education is a social practice of forming young doctors, and influencing a powerful di course. What ethic informs the use of that power by educators? And how can educators "do" ethi in a way which keeps them alert to their ow political positioning, and enables them to ue power appropriately?

\section{Discourse of bioethics}

These questions about medical ethics education need to be situated within the wider discourse of bioethics (of which medical ethics is one subse $\overrightarrow{\epsilon_{J}}$ tion). Here questions of power, discourse, and the social construction of knowledge are only begi尔 ning to have an impact on conversations arid debates. There are pragmatic and historica reasons for this.

Pragmatically, it has not been politically expedî ent to raise certain issues in conversations wiक doctors. Ethicists (in clinical and educationat contexts) have only recently gained access to coroversations about medical practice, and it has nof been politically expedient to promote themselve as questioning medical power. Rather, ethicists have portrayed themselves as seeking to assie good doctors to enhance their practice and to sise to new challenges of technological developments and social change. ${ }^{8}$

Historically, bioethics embraced liberal ind vidualism as the basis of its thinking, with litt attention to social content. ${ }^{9}$ This is hardly surprie ing given that bioethics's early development was largely in the 1960s in the USA. Its developmeng was precipitated by pressures on traditional medical ethics from a combination of social changes, advances in medical care which generated ne issues, alternatives in the pattern of healtw delivery, ${ }^{10}$ and outrage at stories of abusiv research. Philosophers were invited to participat in responding to these fresh challenges and inev? tably did so from within the traditions in which they were trained. For instance, bioethics's roo in liberal individualism are clearly apparent in the writing of the bioethics author who has mos: deliberately engaged with postmodern challenges Tristram Engelhardt. ${ }^{11}$ Engelhardt's response is to ground bioethics in fundamental respect foib autonomy, and in doing so he privileges libera्f individualists within post-modern debates.

Pellegrino's identification of the "period of crisis" which faces bioethics, and Engelhardt work, are recognition of the challenges which fact bioethics as it is presented with multiple voices and increasing participation of peoples from

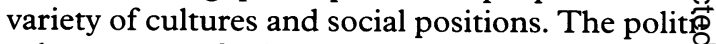
cal nature of theorising has become more 
apparent as feminist critiques are aired, ${ }^{9} 12$ patients' narratives disturb dominant medical constructs of the meaning of illness, ${ }^{13}$ health professionals other than doctors assess the adequacy of dominant approaches, ${ }^{14}$ and bioethicists from places other than North America become more visible. Whether ready or not, issues of difference, "otherness", social positioning and structural power are making themselves known to the fathers of bioethics. The possibilities of objectivity, political detachment and universal theory are fading fast. Bioethics, as a discipline, is beginning to ask itself: whose interests are being served by this discourse? Is bioethics becoming a means by which present social structures and assumptions are supported and regulated? $\mathrm{Or}$ is it a discipline that is contributing to a fundamental questioning of the values that inform relationships between individuals and between different groups? Does bioethics, for example, offer ways of understanding new birth technologies that further regulate and control women within a patriarchal society, or does it contribute to understandings of human reproduction that transform abusive and destructive social relationships between women and men? Relentlessly, bioethicists are finding themselves drawn into messy pragmatics. Theory cannot be detached from clinical and political life.

\section{Bioethics and medical education}

It is perhaps not surprising that the literature on medical ethics education has stepped around these issues. As the discourse of ethics has negotiated a new place for itself within medical curricula, those writing on ethics education in medicine have focused largely on descriptions of strategies in ethics teaching and on assessment of the various methodologies and philosophies associated with ethics itself. (For instance, an issue of the Fournal of Medicine and Philosophy (1991) ${ }^{15}$ devoted to bioethics education, is a reflection upon the philosophies taught in medical education rather than on educational philosophy.) There is little work that discusses the intent of medical ethics education - why we do what we do - or reflects upon the ethical and political implications of medical ethics education.

The intent of medical ethics education is generally described in terms acceptable to medical discourse. Fox et al, for instance, argue that the traditional model "should contribute to students' future clinical competence as physicians by supplying them with knowledge and cognitive skills necessary for ethical decision making". ${ }^{16}$ The literature generally focuses on strategies that fulfil this intent and describes classroom lectures and small group discussions stimulated by a vari- ety of means. Much of this is in the form of reports of ethics teaching at various medical schools. ${ }^{17-21}$ In addition to formal lectures (mentioned in most reports of specific programmes), methods discussed focus on techniques for use in small groups. ${ }^{22-37}$ These reports are largely descriptive. The underlying assumption seems to be that if we teach students to analyse and reflect we will produce ethical practitioners, that cognitive skills are sufficient. We are so busy wanting students to be capable of moral reflection that we pay little attention to the values that underlie the conceptual and social frameworks with which they and we are working.

Other intents that could supplement traditional courses are quietly discussed or assumed. Ethics education could focus on the formation of the student, the development of a particular "character". Ethics education could join forces with medical humanities and be orientated towards an active shaping of students' attitudes, values, moral development and behaviour.

But one could do this without any critical thought about the discourse and practice of medicine itself, and there is little discussion about whether humanising medicine is the appropriate role for ethicists, ${ }^{38}$ or what social and political role ethicists should play in perpetuating or challenging a socially powerful discourse. The silence on this matter leaves ethics educators open to the accusation that we are agents for indoctrinating students into the norms of medical practice, and are avoiding the difficult questions about our own position in the changing and politicised world of medicine. Yet as the discourse of medicine is increasingly questioned, and as more critical voices are raised within the discourse of bioethics, medical ethics educators need to review their own role in medicine. Is it the role of the medical ethics educator to produce doctors who can function well within current medical understandings of ethical practice, or should we be a part of raising critical questions about the practice of medicine itself, and the relationships between knowledge, power and privilege?

If, or when, we engage in questions about our philosophy of education in medical ethics education, on what resources can we draw?

\section{Bioethics: a questioned discourse}

As discussed above, bioethics as a discourse is slowly recognising that it is as subject to social and political positioning as any other discourse. The issues we identify, the questions we ask, and the historical and philosophical frameworks within which we work all place us somewhere. Recognising that, we make value or ethical choices about 
how we use that position, what and whose interests we pursue, what social structures we question, and what support we offer. We are never disinterested observers, but rather active participants in a creation and (re)negotiation of social discourses.

In developing an educational philosophy to inform the teaching of medical ethics, bioethics can benefit from attention to the contributions from those who may not have written the academic texts, but whose voices have provided some of the political impetus behind the development of a discourse of bioethics.

These are the voices of the socially marginalised. The narratives of Tuskegee, Nazi atrocities, American experimentation on orphans, the mentally ill, and indigenous peoples have demonstrated the need for changes in medical and research practice. ${ }^{39}$ More recently it has been the narratives of patients which have asserted themselves above the intellectual chat, and demanded that we pay more attention to the lived experience of illness, disease and accident, and that we allow these narratives to transform our theoretical constructions. Frequently, it has been those who protest and resist social practices who have made us aware that changes in practice and theory are required, rather than the voices of those who were the socially powerful participants in health care.

What these voices remind us is that those who are part of a dominant discourse (which maintains specific arrangements of power) are least likely to be able to notice the ways in which a discourse functions to abuse and oppress. As Welch has argued:

"We can see foundational flaws in systems of ethics only from the outside, from the perspective of another system of defining and implementing that which is valued. In order to determine which interests or positions are more just, pluralism is required, not for its own sake, but for the sake of enlarging our moral vision." 40

The voices of those who are different, other, on the edge of a discourse, or the object of its concern (such as patients in the medical system) are necessary in order to alert us to the impact of a discourse and the changes required in the structures of power and webs of relationship that ethics seeks to inform. As Smith puts it: "[r]elations are not only webs of connection and obligation, they are also historical creations that enforce and reinforce specific arrangements of power". ${ }^{41}$

These issues are, of course, being addressed outside the discourses of bioethics and medicine. Rorty ${ }^{42}$ for instance has suggested that voices on the margins of society are a means to alert peop遮 to undesirable consequences of social practices and institutions. This, however, is using the voices and stories as a safety net, a means to make us less cruel in our living out of a dominar approach to social life. It does not allow the $\overrightarrow{8}$ voices to challenge the discourse itself, to destabef lise the assumptions and values that permeate it $\overline{\overline{\alpha x}}$ question the relationships of power on which $\frac{8}{8}$ discourse is based. Rorty leaves unchallenged the divide between public and private life which oth ers, particularly in the feminist literature, ${ }^{43}{ }^{44}$ have recognised as making possible a silence in ethic th discourse on many issues such as domest violence and control of reproduction.

There are strong parallels here with thi educational approaches that have also emerge from marginalised communities. The "pedagogy of the oppressed" proposed by Freire ${ }^{45}$ argued that education is not neutral - it can socialise people fulfil their given social role, or it can be the means of liberation, providing them with the means transform the social relations of which they are part, not merely becoming the successful dominant partner in a relationship but transforne ing the nature of the relationship itself.

Such an orientation to medical ethics educapoos would support an approach to bioethics which protects itself from domestication by a domision discourse, medicine, and promotes an undee standing of ethics which includes not only ethical reflection on the micro or local level, but also gl the political and social level.

\section{Critical education}

I wish to emphasise at this point that I am nơ advocating the abandonment of the tradition pursuits of teaching ethics: the analytical skillo rational argument, and knowledge of professiong guidelines and codes. I am arguing for the extersion and widening of the issues to include recognition of the social positioning of medicine and ethics.

I argue that in our post-modern world, whe no one construction of knowledge can automati cally claim authority, there are three tasks for bioethics education. We need to teach the traditional skills associated with ethics - analytica skills, rational argument. We also need to make sure students are familiar with professional guide lines and codes agreed to by their profession of required by law, and that they are effectively able to translate these requirements into practice. Bit if we stop here, we are teaching students how to sustain the status quo. This is comfortable for the profession, and what is, I suspect, frequent expected of ethics educators. But there is a thire 
task, required of us by the ethics of discourse which we practise. We need also to be able to be critical educators. It is important to widen the tasks of bioethics education to include recognition of the social positioning of medicine and ethics. Students need to become aware of the various forms of power they are being trained to hold (and hold already by virtue of, for example, their sex, race, or culture), and the ethical choices they make as they decide how to use that power. If students are not aware of, or do not understand, the ways in which power is structured into the social practice of medicine, they are not well equipped to make ethically informed choices about their participation in changing, accepting or resisting those values.

Note, that I am not using "power" as a derogatory word, or with negative connotations. Power is productive, the product of an interweaving of relationships, choices and social positionings. But we are not merely productions of our time and place, determined by external factors. If we are moral beings at all we are capable of choices and decisions about how we use the opportunities that are available, some of which are specific to social position and professional opportunities, structured by the discourses in which we participate.

Here I am open to charges of optimism. Namely, that I am too optimistic if I believe that, having been made more aware of the power they hold as a consequence of their position within a discourse, medical students (and the doctors they become) will choose to use that power to benefit those marginalised within the discourse. There is, of course, no guarantee that they will do so. They may become doctors more skilled at identifying and abusing their power! But a critical approach to education puts power on the agenda and asks students and teachers to examine their own use of power, and to make active choices about subsequent behaviour. In making power visible, participants in a discourse become more accountable for their use of it.

But how to do this, in the midst of a traditional, powerful professional discourse?

\section{The political context for the bioethics educator}

Achieving the creation of such an educational space is a challenge for ethics educators. The possibilities for educators in medical ethics are in part determined by the context in which they work. Bioethicists who are given the responsibility for ethics education in medical schools are not necessarily part of the dominant discourse themselves. Backgrounds may be in philosophy, law, theology or other health professions. The consequence of this is that ethicists are "outsiders within", admitted to the medical discourse, but not strictly of it; more than guests, but not quite family. Like in-laws, ethicists come from a different family system; they belong, but in a particular and peculiar way.

Ethicists, therefore, must negotiate their place in the curriculum, and do so in terms that are acceptable to the medical discourse, the more powerful discourse in this context. Thus, as Brody ${ }^{8}$ has demonstrated, ethicists have shown their worth in helping well-intentioned doctors to do their job better, but have avoided dealing with the issues of power that operate within medicine. Bioethicists have recognised, even if only in their silence on that issue, that their continued presence at the bedside requires them to phrase arguments in terms that can be heard and accepted by the medical world.

\section{Voices of protest}

Yet, as we have seen, many of the changes in medical practice to which bioethicists have contributed have required voices of protest and resistance, the public articulation of subversive narratives and alternative knowledges. Bioethicists employed in medical institutions (whatever their theoretical orientation) walk a delicate line with regard to these alternative voices. If they identify too closely they risk being ignored or marginalised. If they lose sensitivity to them they risk co-option into medical discourse and the loss of ability to do more than provide justification for the power structures of medicine.

There are many implications for educators seeking to teach a critical ethic. They are attempting to introduce the disruptive memories and alternative knowledges which will assist medicine to practise an ethic respectful of difference, and to develop in students an ability to respond adequately to issues of difference and to recognise its place in the construction and maintenance of relationships of power. But this has the following problems.

Firstly, when teaching ethics within medical schools, one needs to find methodologies which "fit" within the institutional framework in which they work. Because ethicists are not integral to the medical discourse they may have little influence over the total medical educational process. However, they may be invited to contribute to specific components of the training, and may also be able to negotiate additional input. But whatever level of integration into the course ethicists may have, what they "do" needs to be acceptable to the medical discourse within which 
they work. Anything too disruptive or too alternative may be counterproductive to efforts to move ethics from a marginal to a more central position in medical discourse.

Secondly, many of the discussions on liberation and education assume that one is working with people for whom education is a vehicle to their own liberation or who are already committed to social transformation. ${ }^{+4 i}$ This is not necessarily so in medical education. One can be working for the emancipation of students (who are not all unoppressed!), but one is also working for emancipation of those outside the medical profession, alerting students to the impact of structural inequalities on their delivery of health care, and the impact of the patterns of oppression which they have internalised, in various forms, within themselves.

In addition, ethicists are contributing to an educational process which is introducing people to a dominant discourse within health care. Ethicists are teaching students the skills and attitudes which will equip them to be members of a profession which already has and uses considerable power, power which is able to be of enormous benefit to patients, but which also can be used for the practitioners' benefit, and to abuse.

Thirdly, there are practical issues within the classroom. To practise and teach an ethic respectful of difference requires an educational process which respects difference in the classroom too. The student body is very diverse. Their social positions will vary widely. Some will be in very privileged social positions, others will have first-hand experience of many forms of oppression - for example, race, gender, sexuality, class. The methods and content need to acknowledge and work with this and contribute to the creation of an environment which allows students to explore the issues of difference in their own experience, and the impact of that upon their medical training and future practice.

\section{Conclusion}

There is, at best, a small whimper about these issues in the literature in medical ethics education. Some accounts of medical ethics education do value the students' voice, and recognise the importance of working with the students' experiences rather than imposing constructs upon their experiences or working with material detached from their practice. ${ }^{26}$ But their experience is not placed within the wider social and political framework of the discourse, nor is the discourse itself problematised. The focus appears to be on assisting the students to position themselves in a sustainable way within the medical world, and help them to survive.

But the times are achanging. Claims objectivity and neutrality are increasingly difficưpt

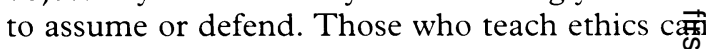
no longer assume (if we ever could) that there $\frac{j}{5}$ some disinterested body of knowledge that impart to students, or some set of universal ethic values that can be uncritically applied to a soci practice such as medicine. We need to lift obbr thinking and engage with the intellectual questions of our time and their implications for medP cal ethics education.

In one sense there is nothing new in all the Intellectual life has traditionally been a pursuit $\overline{\bar{\theta}}$. knowledge, has always implied an openness $\mathbb{S}_{S}$ new thoughts. But socially marginalised peopleूs know that this has not always been true in educa tion. They know that the parameters of acceptab? dissonance have been proscribed by the powerfog, and have excluded many. Teachers of ethics medical students need to attend to the parameteres of thought, and allow the disturbing voices \& criticise the practice of ethics and of the medic profession. In this way ethics educators cain participate in the construction of a medicgl discourse continually open to the possibilitiog of transformation, and to the development of ethical professional practice.

Barbara Nicholas, PhD, is a Lecturer in the Christcis urch School of Medicine, Christchurch, New Zealar Contact address: Department of Public Health a General Practice, Christchurch School of Medici PO Box 4345, Christchurch, New Zealand.

\section{References}

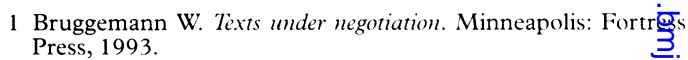

2 Coney S, Bunkle P. An unfortunate experience at National Women's. Auckland Metro 1987;7,72:47-65.
Committee of inquiry into allegations concerning the tre?

3 Committee of inquiry into allegations concerning the tre ment of cervical cancer at National Women's Hospital and ingo other related matters. The report of the committee of inquiry in allegations concerning the treatment of cervical cancer at Nations Women's Hospital and other related matters. Auckland, Nov Zealand: The committee, 1988.

4 Foucault M. Power/knowledge: selected inteviews and other writing 1972-77. Brighton, Sussex: Harvester Press, 1980.

5 Harding S. Whose science? Whose knowledge? Milton Keynjes Open University Press, 1991.

6 Grant J. White women's Christ and black women's Jesus. Atla Wha Georgia: Scholars Press, 1989.

7 Thistlethwaite S. Sex, race and God. London: Geoffey Chapman, 1990

8 Brody H. The healer's power. New Haven and London: Yo University Press, 1992 . 9 Wolf SM, ed. Feminism and bioethics: beyond reproduction. N 10 Pellegrino E. The metamorphis of medical ethics. Fournal of
American Medical Association 1993;269,9:1 158-62.

11 Engelhardt T. Foundations of bioethics. New York/Lond $\mathbb{R}$ Oxford University Press, 1989.

12 Tong R. Feminist approaches to bioethics. Colorado: Westvion Press, 1997. 
13 Frank A. The wounded storyteller: body, illness and ethics. Chicago: University of Chicago Press, 1995.

14 Johnstone M-J. Bioethics: a nursing perspective. Sydney: WB Saunders/Balliere Tindall, 1989.

15 fournal of Medicine and Philosophy 1991;16,1:1-130. .

16 Fox E, Arnold R, Brody B. Medical ethics education: past, present and future. Academic Medicine 1995;70,9:761-9.

17 Hayward RS, Honer WG. Student directed teaching of medical ethics at a Canadian medical school. Fournal of Medical Education 1985;60,5:348-89.

18 Bloch S. Teaching psychiatric ethics. Medical Education 1988;22:550-3.

19 Burling SJ, et al. Review of the teaching of medical ethics in London medical schools. Fournal of Medical Ethics 1990;16,4: 206-9.

20 Elstein M, Harris J. Teaching medical ethics. Medical Education 1990;24,6:531-4.

21 Seedhouse D. Teaching analysis. Health Care Analysis 1995;3: 71-4.

22 Durbin PT, Engel JD, Blacklow RS. Sensitizing residents to moral issues by case discusssions. Academic Medicine 1991; 66,10:588

23 Kuczewski M, Wicclair MR, Arnold RM, Pinkus R, Aumann GME. Make my case; ethics teaching and case presentations. Fournal of Clinical Ethics 1994;5,4:310-15.

24 Stevens NG, McCormick TK. Teaching medical ethics: what are students thinking when we present ethics cases? An example of focusing on confidentiality and substance abuse. fournal of Medical Ethics 1994;20,2:112-17.

25 Osborne LW, Martin CM. The importance of listening to medical students when teaching them medical ethics. Fournal of Medical Ethics 1989;5,1:35-8.

26 Christakis D, Feudtner C. The ethical consequences of transient social relationships in medical training. Fournal of the American Medical Association 1997;278,9:739-42.

27 Moore A. Medical humanities: an aid to ethical discussions. fournal of Medical Ethics 1977;3:26-32.

28 Radaway SM, Adelson BH. The use of literary classics in teaching medical ethics to physicians. Fournal of the American Medical Association 1987;257:1629-31.

29 Calman KC, Downie R, Duthie M, Sweeny B. Literature and medicine; a short course for medical students. Medical Education 1988;22:265-9.
30 Sheriff DS. Literature and medical ethics. Royal Society of Medicine 1988;8,12:688-90.

31 Waldron EE. Using literature to teach ethical principles in medicine: of mice and men and the concept of duty. Literature and Medicine 1988;7:170-6.

32 Nixon LL. Patients are more than their illnesses: the use of story in medical education. Law, Medicine and Health Care 1990;18,4:419-21.

33 Metzger N. Improving communication in health care: the uses of literature. Second Opinion 1992;17,3:57-68.

34 Self D, Baldwin DC. Teaching medical humanities through film discussion. Fournal of Medical Humanities 1990;11,1:23-9.

35 Hensel WT, Rasco TL. Story telling as a method for teaching values and attitudes. Academic Medicine 1992;67,8:500-4.

36 Nelson MS, Eliastam M. Role-playing for teaching ethics in emergency medicine. American fournal of Emergency Medicine $1991 ; 9,4: 370-4$

37 Grant VJ. Advanced medical ethics symposia for fifth year students. Fournal of Medical Ethics 1989;15,4:200-2.

38 Porto E. Social context and historical emergence: the underlying dimensions of medical ethics. Theoretical Medicine 1990;11: 145-65.

$39 \mathrm{McNeill}$ PM. The ethics and politics of human experimentation. Cambridge: Cambridge University Press, 1993.

40 Welch S. A feminist ethic of risk. Minneapolis: Fortress Press, 1990.

41 Smith R. Relationality and the ordering of differences in feminist ethics. Fournal of Feminist Studies in Religion 1993;9,1-2: 199-214.

42 Rorty R. Contingency, irony and solidarity. Cambridge: Cambridge University Press, 1989.

43 Tronto J. Moral boundaries. New York London: Routledge, 1993.

44 Cole EB, Coultrap-McQuin S, eds. Explorations in feminist eth$i c s$. Bloomington Indianapolis: Indiana University Press, 1992.

45 Freire P. Pedagogy of the oppressed. Harmondsworth: Penguin, 1972.

46 Ellsworth E. Why doesn't this feel empowering? Working through the myths of critical pedagogy. Harvard Educational Review 1989;59,3:297-323.

47 Hooks b. Feminist theory: from margin to centre. Boston: South End Press, 1984. 